\title{
ADENOSINE DIPHOSPHATE GLUCOSE AND STARCH SYNTHESIS
}

\author{
E. RECONDO AND L. F. LELOIR \\ Instituto de Investigaciones Bioquimicas, Fundación Campomar \\ and Facultad de Ciencias Exactas y Naturales, Obligado 2490, Buenos Aires, Argentina
}

In previous papers (Fekete et al., 1960; Leloir et al., 1961) an enzyme was described which catalyzes glucose transfer from uridine diphosphate glucose (UDPG) to starch or oligosaccharides. Several synthetic nucleoside diphosphate sugars have now been tested with the same enzyme preparation. They were prepared following the procedures developed by Khorana and others (Roseman, Distler, Moffatt and Khorana, 1961) with slight modifications. The most interesting result was that adenosine diphosphate glucose (ADPG) reacts about tenfold faster than UDPG. A typical experiment is shown in Fig. 1.
Addition of ADPG to radioactive UDPG led to a decrease in the incorporation of radioactivity in starch (Table I). The inverse, that is, addition of UDPG to labeled ADPG did not produce any change. Table I also shows that the difference in rate of transfer as estimated by UDP and ADP formation is also observable when incorporation of radioactivity into starch is measured.

As in the experiments with UDPG (Leloir et al., 1961) the glucose transferred to starch was found to be distributed between the amylose and amylopectin components.

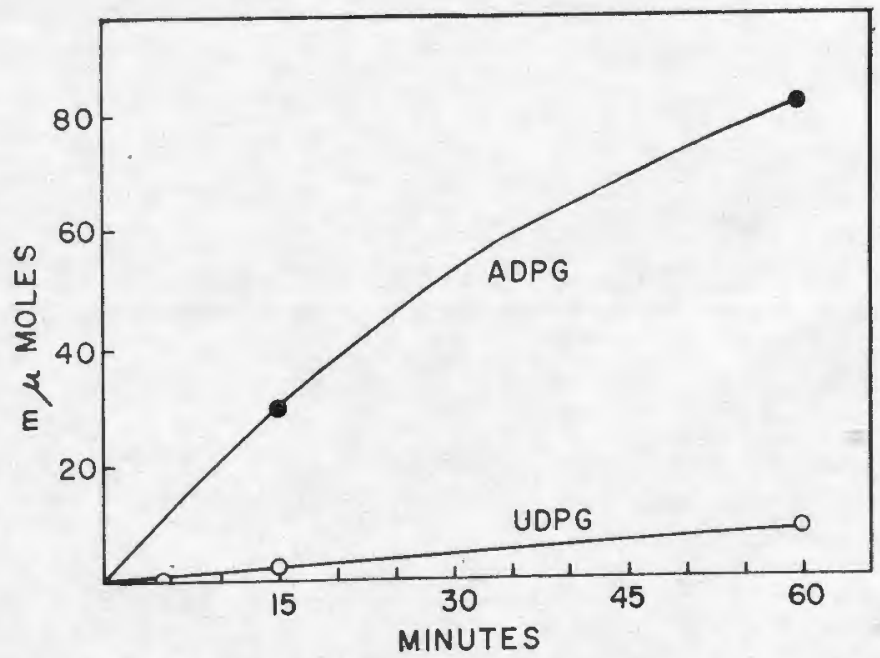

Fig. 1. - Formation of ADP or UDP. Reaction mixture (in $\mu$ moles): 0.25 of substrate, 0.1 of

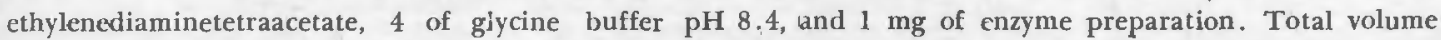
$0.02 \mathrm{ml}$. Temperature $37^{\circ}$. UDP (or ADP) measured with pyruvatekinase (Leloir and Goldemberg, 1960) after addition of $0.4 \mathrm{ml}$ of $75 \%$ methanol, centrifugation and evaporation of the supernatant fluid. 
A transfer of glucose to added oligosaccharides takes place with ADPG as in the case of UDPG. Thus as shown in Table II, addition of maltotriose to labeled ADPG and enzyme, led to the formation of radioactive oligosaccharides and to a decrease in the in-

TABLE I

\begin{tabular}{|c|c|c|c|c|}
\hline & \multirow{2}{*}{ Additions } & \multicolumn{3}{|c|}{$\begin{array}{l}\text { Glucose transferred to } \\
\text { starch }\end{array}$} \\
\hline & & & c.p.m. & $\mathrm{m} \mu \mathrm{moles}$ \\
\hline UDPG-O14 & $(9,500$ c.p.m.) & - & 242 & 6.4 \\
\hline UDPG-C 14 & (9,500 c.p.m.) & $+\mathrm{ADPG}$ & 58 & 1.5 \\
\hline ADPG-C14 & (1,000 c.p.m.) & - & 478 & 72.0 \\
\hline ADPG-C.14 & $(1,000$ c.p.m. & + UDPG & 488 & 73.0 \\
\hline
\end{tabular}

Reaction mixture as in figure 1 with $0.25 \mu$ mole of substrates (except ADPG-C14 of which $0.15 \mu$ mole was added. It was prepared with equimolecular amounts of adenosine 5'-phosphate morpholidate and glucose 1-phosphate-(14). Total volume $0.03 \mathrm{ml}$. Incubation time $50 \mathrm{~min}$. Measurements as described by Leloir et al. (1961).

corporation into starch. Paper chromatography showed that the labeled oligosaccharide was mainly maltotetraose. The results are similar to-those previously obtained with UDPG.

\section{TABLE II}

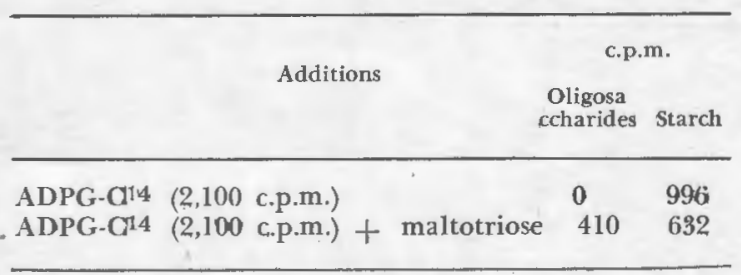

Reaction mixture as in figure 1. Maltotriose 0.67 $\mu$ mole. Total volume $0.03 \mathrm{ml}$. Incubation time 1 hour.

\section{REFERENCES}

Caputto, R., Leloir, L. F., Cardini, C. E. and PaLAdini, A. C., J. Biol. Chem. 184, 333 (1950).

Cardini, C. E., Leloir, L. F. and Chiriboga, J., J. Biol. Chem. 214, 149 (1955)

Fekfte, M. A. R. DE, Leloir, L. F. and Cardini, C. E., Nature 187, 918 (1960).

Goldemberg, S. H., Biochin et Biophys. Acta (submitted for publication).
No formation of nucleoside diphosphate was detected when the enzyme was incubated with any of the following compounds: inosine diphosphate.glucose (obtained by deamination of ADPG with nitrous acid), cytidine diphosphate glucose, guanosine diphosphate glucose, ADP-maltose, ADP-galactose or UDP-galactose. Furthermore the $\beta$-anomers of ADPG and UDPG gave negative results, as also did an isomer of ADPG in which the glucose is joined to ADP through position 6 .

ADPG has been tested with several other systems which are known to use UDPG. The synthesis of glycogen by muscle (Goldemberg, 1961), liver, and yeast preparations was about half as fast when ADPG was substituted for UDPG. Other systems which were tested with ADPG and gave negative or nearly negative results were: the galactowaldenase system (Caputto et al., 1950), and sucrose or sucrose phosphate synthesis (Cardini et al., 1955; Leloir and Cardini, 1955) .

From the above mentioned results it seems that ADPG and UDPG react with the same enzyme and the question arises as to whether ADPG has a role in starch synthesis "in vivo'.' There is one fact which indicates that ADPG may be a normal metabolite, and this is the presence of an ADPG-pyrophosphorylase in plant material. This enzyme which is being studied in this laboratory by Dr. J. Espada catalyzes the formation of ADPG from adenosine triphosphate and glucose 1-phosphate. It seems to be a different enzyme from UDPG-pyrophosphorylase.

\section{ACKNOWLEDGMENTS}

This investigation was supported in part by a research grant (No G-3442) from the National Institutes of Health, U. S. Public Health Service, by the Rockefeller Foundation and by the Consejo Nacional de Investigaciones Científicas y Técnicas.

Lelotr, L. F. and Cardini, C. E., I. Biol. Chem. 214, 157 (1955).

Leloir, L. F. and Goldemberg, S. H., J. Biol, Chem. 235, 919 (1963).

Leloir, L. F., Fekete, M. A. R. de and Cardini, C. E., J. Biol. Chem. 236, 636 (1961).

Roseman, S., Distler, J. J., Moffatt, J. G. and KhoRANa, H. G., J. Am. Chem. Soc. 83, 659 (1961). 